\title{
Task Force Report 2. Report of the Task Force on Medical Education
}

\author{
Jobn R. Bucboltz, DO' \\ Samuel C. Matbeny, MD, MPH² \\ Perry A. Pugno, MD, MPH, CPE \\ Alan David, $M D^{4}$ \\ Erika B. Bliss, $M D^{5}$ \\ Eliana C. Korin, Dipl Psic \\ 'Chair, Task Force 2, Columbus, Ga \\ ${ }^{2}$ Vice Chair, Task Force 2, Lexington, Ky \\ ${ }^{3}$ Staff Executive, Task Force 2, Leawood, Kan \\ ${ }^{4}$ Member, Task Force 2, Milwaukee, Wisc \\ ${ }^{5}$ Member, Task Force 2, Seattle, Wash \\ ${ }^{6}$ Member, Task Force 2, Bronx, NY
}

\begin{abstract}
BACKGROUND For family physicians to be prepared to deliver the core attributes and system services of family medicine in the future, especially within the New Model of family medicine that has been proposed, changes will need to be made in how family physicians are trained. This Future of Family Medicine task force report presents a plan for implementing appropriate changes in medical school and residency programs.
\end{abstract}

METHODS As a foundation for the development of specific recommendations on medical education, this task force reviewed relevant findings from research conducted for the Future of Family Medicine project and presents an historical perspective of the specialty. We addressed accreditation criteria for family medicine residency programs and examined various relevant projects and programs, including the Academic Family Medicine Organizations/Association of Family Practice Residency Directors Action Plan, the Residency Assistance Program Criteria for Excellence, the Accreditation Council for Graduate Medical Education Outcome Project, the Family Medicine Curriculum Resource Project, and the Arizona Study of Career Selection Factors. The task force relied on the Institute of Medicine report, Health Professions Education: A Bridge to Quality, as a foundation for proposing a new vision and mission for family medicine residency education.

MAJOR FINDINGS The training of future family physicians must be grounded in evidence-based medicine that is relevant to the care of the whole person in a relationship and community context. It also must be technologically up to date, built on a solid foundation of clinical science, and strong in the components of interpersonal and behavioral skills. Family physicians must continue to be broadly trained and have the competencies required to practice in a variety of settings. It is important that training in maternity care and training in the care of hospitalized patients continue to be included in the family medicine residency curriculum, but programs must be allowed to tailor that curriculum to be compatible with educational resources and individual trainee needs.

CONCLUSION Given the changes taking place in the specialty and within the broader health care system, it is clear that the traditional family medicine curriculum, although successful in the past, cannot meet the needs of the future. The educational process must train competent family physicians who will provide a personal medical home for their patients, a key concept that must be an integral part of whatever new systems are designed. Such competency will require family physicians who understand and practice process-oriented care, who utilize the biopsychosocial model to create superb physician-patient relationships, who actively measure outcomes, and whose practices are driven by information system access to evidence-based principles of care.

Ann Fam Med 2004;2:S51-S64. DOI: 10.1370/afm.135.

TASK FORCE CHARGE: Determine the training needed for family physicians to deliver the core attributes and system services.

\section{INTRODUCTION \\ T nlike many other specialties, family medicine is not defined by content (ie, a specific list of services), by the age or gender of the patient population served, or by the setting in which care is pro-}


vided. Rather, the family physician's knowledge, skills, and attitudes encompass all ages, both genders, a myriad of complaints and illnesses, and multiple settings. As such, the education of the family physician is one that emphasizes a process: the patient-physician relationship and problem definition and prioritization. The family physician uses the same process in the approach to all patients and is an expert in this process-oriented discipline. Because of these characteristics, and the emphasis of the specialty on continuity and comprehensiveness of care, the family medicine practice is ideally suited to serve as a medical home for most Americans.

Family medicine residency education began with a number of innovations more than 30 years ago that have influenced residency education in other specialties. Its full potential has not been realized, however. Changes in both the practice environment and in residency education have created a need to reevaluate and revise the traditional family medicine training model. Among the changes that have taken place since the specialty was created are the following: few residency graduates now go into solo practice, only about one third of graduates include maternity care in their scope of services, and many new graduates provide little or no inpatient care. ${ }^{1}$ In addition, evidence-based, quality- and outcome-oriented medicine are driving forces today.

Given these and other changes, it is clear that the traditional family medicine curriculum, although successful in the past, cannot meet the anticipated needs of the health care system of the future. Family medicine, at both the graduate and undergraduate levels, must refocus and create models that support future needs, by educating family physicians whose core knowledge, skills, and attitudes have been measured and whose special interests and competencies have been developed to a level of unquestioned excellence.

The core experience responsible for the formation of the family physician is residency training ${ }_{i}$ therefore, the creation of the family physician of the future will depend on the creation of a new paradigm for residency education. Family physicians of tomorrow will need to have knowledge, skills, and attitudes that go beyond diagnosis and treatment of disease, including skills in health promotion designed to maximize each patient's potential. In addition, the family physician of the future will need to be an expert manager of knowledge (information systems expertise), relationships, and resources.

\section{HISTORICAL CONTEXT}

Family medicine is well grounded in a history of service to patients, strong educational training, social commitment, and expertise in managing the complexity of health care. In September 1964, the Council on Medi- cal Education of the American Medical Association appointed the Ad Hoc Committee on Education for Family Practice. The challenge to the Ad Hoc Committee in 1964 is the challenge of this task force today: "As society becomes more highly organized and complex, and as science and technology of medicine advance, the need grows to find better and more efficient ways of providing personalized care for patients."

\section{Residency Review Committee for Family Prac- tice-Accreditation Criteria}

The first Residency Review Committee for Family Practice (RRC-FP) accreditation requirements were less than 2 pages. Interestingly, there were already published guidelines for residency training in general practice in addition to those for family medicine. General practice training was a 2-year endeavor compared with the 3 years that has evolved for family medicine.

To meet the Ad Hoc Committee's charge of flexibility in training, the first guidelines specifically stated that it was not essential, nor desirable, that all programs be rigidly uniform. General curricular areas of family medicine, internal medicine, pediatrics, psychiatry, obstetrics and gynecology, surgery, community medicine, and research were outlined by the approximate percentage of time that should be allocated to each.

Subsequent revisions to the requirements were issued in 1975, 1981, 1985, 1994, 1997, and 2000. Each was an attempt to respond to the evolving health care system (eg, focus on prevention, practice management), changes in demographics (eg, geriatrics, cultural competency), emerging issues (eg, care of patients infected with the human immunodeficiency virus, sports medicine), and new concepts in the science of education (eg, formative evaluations, competencies). The 1985 version expanded the specifics of study under each curricular area, mandating periods of time for most experiences, as well as a required core curriculum for all programs. This version became the template for the current requirements.

In response to various pressures within and outside medicine, the family of family medicine organizations and the specialty's governing bodies continue to work on revisions of the guidelines for family medicine education.

\section{AFMOIAFPRD Action Plan}

The Academic Family Medicine Organizations/Association of Family Practice Residency Directors (AFMO/AFPRD) plan, ${ }^{2}$ published in August 2002, set out to create a plan that would achieve the following objectives:

- Educate a sufficient number of family physicians to meet the health care needs of the American public.

- Provide an appropriate sponsor mix for the nation's family medicine residencies. 
- Provide the training necessary to be responsive to the health care needs of the American public.

- Provide family medicine residencies with sufficient family physician and other residency faculty.

- Effectively utilize family medicine residency programs to educate a variety of learners in the principles of family medicine.

The plan was divided into 3 general areas: organizational, clinical, and community competencies. Organizational competencies included working as a member of a team, ensuring high-quality care, and using computerized information systems. Clinical competencies focus on the scope of practice, emphasizing procedures, clinical testing, and innovative approaches to the family medicine center. Community competencies focus on community-oriented primary care (COPC) and service to vulnerable and underserved populations. While the action plan was neither a complete review of family medicine residency education nor a blueprint, it did begin to organize residency education differentlyaway from a focus on the specialty components of family medicine (pediatrics, adult medicine, obstetrics and gynecology, surgery, etc) toward a unifying framework based on broad categories of competencies.

\section{RAP Criteria for Excellence in Family Medicine Education}

The Residency Assistance Program (RAP) criteria for excellence, last updated in January 2003, also recognized that the health care environment and the practice of family medicine had outpaced family medicine residency education, and that a restructuring and reorganizing of the process, as well as some of the content and options in family medicine residency education, were needed. The RAP criteria were organized differently from the AFMO/AFPRD action plan, emphasizing the "why, what, and how" of residency education. The "why" addressed the idea that any residency program should know "what purposes and stakeholders it serves and how its overall effectiveness can be measured," and should have a strategic plan, a philosophy, and a clear blueprint for the program's future. The "what" addressed the curriculum of the residency program, which must "define the purpose, methods, and educational philosophy, and the competencies of [the] residency's graduates." The "how" addressed the organization, sponsoring and participating institutions, faculty, residents, resources, and downstream impact of the program, identifying crucial structural components that must be in place to support a program of excellence.

\section{The ACGME Outcome Project}

With the onset of the mandate of the Accreditation Council for Graduate Medical Education (ACGME) toward competency-based education, the specific needs of the learners and the flexibility of programs to meet those needs becomes more important. This perspective is captured in the ACGME outcome project. ${ }^{3}$ The project, which began in 1998, mandates that residency programs in all disciplines be required to address 6 central competencies (although programs will have flexibility to incorporate personal and regional needs). These following competencies were accepted by the ACGME board in February 1999 and took full effect in July 2002:

1. Medical knowledge

2. Patient care

3. Communication skills

4. Professionalism

5. Practice-based learning and improvement

6. System-based care

\section{The Family Medicine Curriculum Resource Project}

The Family Medicine Curriculum Resource Project is being funded through a 4-year (2000-2004) federal contract awarded by the Health Resources and Services Administration (HRSA) to the Society of Teachers of Family Medicine (STFM). The goal of the project is to develop a resource for use by medical educators to design and implement curricula to prepare medical students for practice in the 21 st century. The end product will address family medicine's contributions to all 4 years of medical student education and is expected to impact the education of all medical students.

The resource is being developed in collaboration with educators in general internal medicine and general pediatrics and will include the following:

- Strategies dedicated to the preclerkship education of all students

- Prerequisite competencies for entering third-year clerkships

- Materials that define the family medicine clerkship's contribution to the development of the clinical skills of all medical students

- Materials dedicated to post-clerkship preparation of medical students seeking residency training in family medicine or related primary care disciplines

Additionally, the Family Medicine Curriculum Resource Project will address the following curricular areas of particular interest to HRSA:

- Genetics

- Oral health

- Geriatrics

- End-of-life care

- Informatics

- Healthy People 2010 objectives

- Substance abuse, including mental health 
The 6 ACGME competencies provide an overarching framework for the Family Medicine Curriculum Resource end product to create a continuum between medical student education and residency training. A tiered, Web-based end product is envisioned, including one tier for decision makers and several more tiers to allow users to seek resources and access varying degrees of depth, according to institutional and user needs.

Two work groups are in the process of using the ACGME framework as a guide for developing the Family Medicine Curriculum Resource end product:

The Preclerkship Collaborative Workgroup, including equal representation from family medicine, internal medicine, and pediatrics, has identified 6 key areas for emphasis in the decision-maker tier. These areas include modern clinical epidemiology, data gathering in the real-world, life cycle issues, communication skills, systems of care, and professionalism.

The Family Medicine Clerkship/Post-Clerkship Workgroup, which consists of educators from family medicine predoctoral and residency programs, has identified 3 vectors that distinguish the family medicine clerkship curriculum: prevention and wellness, acute and chronic illness management, and community and population-based medicine. The group is working to establish general competencies in these areas and crossreference these with the ACGME competencies. The next phase of development will focus on topics important to family medicine, along with the 7 HRSA topics. A module on bioterrorism was developed to pilot the conceptual framework.

\section{The Arizona Study of Career Selection Factors}

As a result of an ongoing decline in interest in Family Medicine Residency Programs, the American Academy of Family Physicians contracted with the Department of Family and Community Medicine at the University of Arizona to investigate factors related to choice of family medicine as a specialty. This effort, known as the Arizona Study, was designed in 2 parts. The first part was a review, assessment, and synthesis of the literature concerning family medicine as a specialty and career choice. The second portion of the project measured specialty choice at 24 US medical schools representing schools showing both increases and decreases in the number of students entering family medicine residency programs.

Among the key findings that were reported upon conclusion of the study in 2002 were the following:

- Medical student interest in the specialty of family medicine peaked in 1997, with $22.3 \%$ of seniors in US medical schools matching in family medicine residency programs. Since then there has been an ongoing downward trend for US seniors selecting family medicine. In
2002, US senior students matched to family medicine had decreased to $10.5 \%$, and in the 2003 the Match rate was $9.2 \%$

- A review of the literature since 1993 showed a possible correlation between selection of family medicine and lower socioeconomic status and lower parental income and education. Also positively correlated to selecting family medicine were rural background (or an intention to practice in a rural area) and interest in family medicine at matriculation to medical school. Other correlating factors were being married, female, or minority status.

- A clerkship in the clinical curriculum and exposure to competent family medicine faculty in medical school were positive correlates for choosing a family medicine residency, as was support from the medical school administration.

- Negative predictors included a high-income expectation, an intention at medical school admission for a non-family-medicine career choice, and interest in a research or academic career.

- A stated career goal of family medicine before medical school was not important, but stated choice after admission was important. There is a phenomenon of recruitment of students into family medicine who expressed little or no interest previously.

- No conclusions could be drawn concerning the influence of medical school debt as it relates to specialty selection.

\section{Implications of FFM Research Findings}

In keeping with the Future of Family Medicine (FFM) project research findings, the results of other recent studies, and the mission of the FFM project, it is clear that the training of future family physicians needs to be grounded in evidence- and scholarship-based medicine and be technologically up to date, community centered, and strong in the components of interpersonal and behavioral skills. Family medicine educators must be able to assure the public and all constituents that family physicians are qualified and competent in a core set of skills. Family physicians will continue to face challenges in health care, but they must learn to adapt, to be truly capable lifelong learners, to use new innovations and advances to further patient well-being, and to interact skillfully with every sector of the health care community. The survival of family medicine as a discipline depends on this skill set.

\section{THE CORE ATTRIBUTES OF FAMILY MEDICINE}

As part of the research that was conducted for the FFM project, attitudes of the public on some of the 
core attributes of the specialty of family medicine were explored. For purposes of the research, the following attributes were examined: continuity of care, comprehensiveness, first contact, community, and family. The findings relating to each have implications for design of the future educational model for family medicine.

\section{Continuity of Care}

Continuity of care, as conceptualized in the FFM research, has 4 dimensions: a relationship developed over time, presence across all points of care, interaction with subspecialists for the good of the patient, and a first-hand understanding of a patient's medical history. FFM research findings assert that the notion of continuity of care does not convey adequately the primary benefit of deeply rewarding relationships. Definite discrepancies, however, exist in the perception of the need for continuity as surveyed by the FFM research project. Because the focus of the questions was on geographic continuity (ie, "the one office where your doctor works") rather than temporal continuity (ie, a family physician providing care over the course of a patient's lifetime in various settings, such as the office, the hospital, a nursing home, etc), public attitudes toward the concept of continuity were mixed. This finding may be because continuity of care is generally not valued by patients unless they have experienced it before or are sick enough to be afraid and want "their doctor" to care of them. Otherwise, some patients may simply place convenience higher than continuity and want a physician who can see them at a convenient time and place for minor problems.

Coordination of care, however, appears to be important to all groups, and first-hand knowledge of patients appears to be highly valued. The challenge is to provide high-quality coverage, 24 hours a day, 7 days a week, 365 days a year, without producing physician burnout. Also, the perception that the family physician needs to always be available for a patient's needs may be deterring some medical students from selecting the discipline.

Continuity of care has the following implications for medical education:

- There is an increased emphasis on coordination of care and developing relationships in which the family physician serves as an advocate for his or her patients.

- There is emphasis on training students in new models of team-oriented care that can promote and preserve continuity.

- There is emphasis on improvement of patient information and knowledge so that family physicians can perform more effectively their advocacy role on behalf of patients.

\section{Comprehensiveness of Care}

The FFM research report explored the following 4 dimensions of the concept of comprehensiveness: treatment of a wide range of medical problems, adherence to the biopsychosocial model, commitment to preventive care, and care across all demographics. The findings demonstrated a problem with believability and ownability of the concept of comprehensive care. Interestingly, while people seemed to question the notion that any one physician could be competent to treat a multiplicity of problems, that characteristic seems to be precisely the attribute valued in primary care physicians by the public.

Comprehensiveness of care has the following implications for medical education:

- Residency education needs to develop better systems for teaching information management.

- Continued emphasis on the biopsychosocial model appears to be important, and efforts to improve the training in this area should be explored.

- Preventive care, as well as patient education on maintenance of healthy life-styles, should be emphasized.

- There may need to be an increased distinction in training programs between understanding family dynamics and its impact on the individual patient as opposed to treatment of the family as a patient (ie, family therapy).

- Appropriate and up-to-date patient management through use of electronic means such as the Internet with clinical guidelines and use of evidence-based medicine should be part of the education process of all residents.

\section{First Contact}

The concept of first contact for purposes of the FFM research has 4 dimensions: a point of entry into a complicated health care system, patient advocacy within the system, accessibility, and appropriate and informed referrals. Among the findings of the research were that some patients equate point of entry with "gatekeeper," that health care professionals view patient advocacy as a unique area of opportunity for family physicians; and that family physicians recognize they are not as accessible as they should be, mainly because of the impact of managed care.

First contact has the following implications for medical education:

- Advocacy is highly valued by all, and there appears to be a need to provide additional emphasis on this aspect in residency training.

- Accessibility is important, to the extent that future physicians can control or manage their own practices. Emphasis on office management techniques that would ensure improvement in this area, such as efficient scheduling and asynchronous communication 
(eg, through e-mail, Web portal, and voice mail) are important.

\section{Community}

According to the FFM research data, the focus on community by family medicine is one of the specialty's best kept secrets, and the discipline's commitment to community and population-based medical care needs to be communicated more effectively. Family physicians do not often point to their ability to leverage community resources as a key patient benefit.

Community has the following implications for medical education:

- It reemphasizes the teaching of community medicine in the broadest terms, with the challenge of incorporating this training into a program currently crowded with clinical content.

- There is a need to devise methods to teach community medicine effectively and to identify metrics by which to evaluate it.

\section{Family}

A seeming paradox is that while the discipline of family medicine places the concept of the family as core to the uniqueness of the discipline, this attribute does not appear to be viewed in this way by many family physicians. For example, only $59 \%$ of family physicians mentioned family as being important in the practice of family medicine. The FFM research suggests the need to redefine the focus on family in broader terms, because the notion of family is variable and often in flux.

Family has the following implications for medical education:

- Place primary emphasis on the impact of the family on the health of the individual patient and secondary emphasis on the treatment of the family as a patient, because many practices have only one family member in a practice.

- Increase sensitivity to the wide range of arrangements inherent in the concept of family in current American society, with the knowledge that many individuals do not consider themselves part of a traditional family unit and that this term may actually be a turnoff for a considerable portion of patients.

- Renew emphasis in behavioral science training on the issues of developing meaningful relationships with patients that can foster a healthy environment.

\section{THE PIPELINE OF FUTURE FAMILY PHYSICIANS}

A subset of the FFM research focused on the pipeline of future physicians: medical students, current family medicine residents, and non-family-medicine specialty residents. The findings, which were similar to those in the Arizona Study, included the following:

- When asked what medical specialty medical students were leaning toward when they finished medical school, the most common choice was family medicine (21\%) followed by internal medicine (16\%). The survey showed that most students start thinking about specialty choice early in their medical education, with $64 \%$ of students thinking about specialty choice before medical school or during the first year of medical school.

- Medical students said "extremely important" or "very important" factors when choosing a medical specialty were that the specialty be intellectually stimulating (92\%) and that the specialty provide an opportunity to make important contributions in people lives (92\%). The most important factors in choosing a medical specialty were satisfaction and happiness in practicing that specialty.

- Training experiences and preceptors were important factors in specialty selection. When asked about the direct influences in choosing a medical specialty, students listed experiences gathered during training rotations $(85 \%)$ followed by physicians met during training rotations $(72 \%)$ as either extremely important or very important. Students listed patient relationships $(40 \%)$, continuity of care $(23 \%)$, and variety (22\%) as the benefits of going into family medicine. Income was cited as the chief drawback to a career in family medicine $(35 \%)$.

- Students at medical schools are likely to perceive family physicians as being held in lower regard than general internists, although students see family physicians and general internists as having similar types of practices. Students, however, feel that family medicine is promoted more $(30 \%)$ by the family medicine faculty than is internal medicine $(17 \%)$ by its internal medicine faculty. Medical students hear the message at school that there continues to be a shortage of family physicians and that the specialty provides an opportunity to develop good physician-patient relationships.

- Family medicine residents decided on their specialty earlier than residents of other specialties, with $36 \%$ of family medicine residents selecting their specialty in the first year of medical school or before compared with $5 \%$ of other specialty residents. Most family medicine residents $(76 \%)$ considered other specialty choices before deciding on family medicine. The most common non-family-medicine specialties considered by family medicine residents are pediatrics (33\%), internal medicine $(30 \%)$, obstetrics and gynecology $(18 \%)$, and emergency medicine (18\%).

- Current family medicine residents listed variety (95\%), making an important contribution to other peoples lives (93\%), developing long-term relationships 
with patients (92\%), and satisfying relationships (91\%) as either extremely important or very important in the career-selection process.

- Family medicine residents (86\%) and specialty residents $(88 \%)$ were extremely happy or very happy with their specialty choice, and $95 \%$ of family medicine residents had no regrets about family medicine as a specialty choice.

- The medical school family medicine rotation was either extremely influential or very influential $(80 \%)$ in the decision to pursue family medicine. More than $90 \%$ of family medicine residents took a family medicine rotation in medical school, with $80 \%$ of the rotations occurring in the third year.

- Specialty residents tend to see family medicine and general internal medicine residents as practicing similar medicine, although the impression of the specialty residents is that internal medicine residents are more thoroughly trained. Specialty residents listed variety, dealing with all patient ages, and providing care for the entire family as the primary benefits of pursuing a career in family medicine. Family medicine residents perceived general, but not strong, support of family medicine by their medical schools and non-familymedicine faculty.

\section{CONTENT OF THE PRACTICE OF FAMILY MEDICINE}

Based on the conceptual framework of the family medicine system of care, family medicine should offer the following for all men, women, and children:

- Health assessment (evaluation of health and risk status)

- Health promotion (primary prevention and health behavior and lifestyle modification)

- Disease prevention (early detection of asymptomatic disease)

- Patient education and support for self-care

- Diagnosis and management of the most common acute injuries and illnesses (the content of this area should be based on data available on the most common presentations for acute care)

- Diagnosis and management of chronic diseases (the content of this area should be in line with those chronic diseases identified as having the greatest negative impact on health and function of the US population)

- Participation in the care of hospitalized patients (not necessarily full responsibility for minute-to-minute care)

- Participation in maternity care (not necessarily including perinatal services)

- Coordination and provision of rehabilitative services

- Supportive care, including end-of-life care
- Primary mental health care

- Coordination and integration of care with other health services

- Preparation for practice in rural, suburban, and urban settings

- Advocacy for the patient within the health care system

Additionally, the content should include services to both the family medicine system of care as well as the larger health care system:

- Continuous quality improvement

- Research on best practices, treatments, and outcomes that matter to patients, improving systems of care, and public health measures as they pertain to family physicians' services and patients

- Integration with and service to the public health system

- Participation in design, planning, and implementation of changes in the larger health care system

Not all family physicians will do all of these things. All residents, however, should be trained to some level of minimum competency in all these areas, with individuals naturally pursuing greater expertise in certain areas and less in others. This choice will reflect both community needs and individual interests. In any local manifestation of the family medicine system of care, however, the provision of all these services must be guaranteed through a coordinated, identifiable group of family physicians who work together at some level and have established methods of communication among members of that group. Canadian family physicians, for example, have conceptualized this as a basket of services whereby a practice or clinic would be made up of various family physicians who do not do everything individually, but as a group provide all the necessary services for their patients.

\section{Current Residency Training Content}

The family medicine residency curriculum has evolved substantially during the past 30 years to meet the changing health care needs of the nation and to better prepare family physicians to deliver the kind of comprehensive, compassionate, and continuous care the public wants and needs. The majority of curricular elements presently incorporated in family medicine graduate medical education remain pertinent and necessary to the current and evolving health care environment. Some curricular elements must continue to evolve, however. To remain relevant in a changing environment, new elements must be added to address emerging issues in health care, and new knowledge of educational content delivery and assessment must be incorporated.

Family physicians must continue to be broadly trained and competent to practice in a variety of set- 
tings. Maternity care, for example, should continue to be included in the family medicine residency curriculum, but training programs must be allowed to tailor that curriculum to be compatible with educational resources and individual trainee needs. For example, the RAP criteria for excellence describe 3 levels of maternity care curricula that address those differing resources and needs. Similarly, the care of hospitalized patients remains an essential component of family medicine residency training. Although some programs may provide more extensive preparation than others, all family medicine residency graduates must be competent in the care of hospital inpatients.

\section{IMPLICATIONS FOR RESIDENCY EDUCATION IN FAMILY MEDICINE}

In a follow-up to the Chasm Report, ${ }^{4}$ the Institute of Medicine (IOM) recently published Health Professions Education: A Bridge to Quality. ${ }^{5}$ The report claims that health professions education has not kept pace with "changes in patient demographics, patient desires, changing health system expectations, evolving practice requirements and staffing arrangements, new information, a focus on improving quality, or new technologies." The report calls for a new overarching vision for all health professions education.

All health professionals should be educated to deliver patient-centered care as members of an interdisciplinary team, emphasizing evidence-based practice, quality improvement approaches, and informatics.

Five competency areas are proposed as the foundation for all health professions education:

1. Patient-centered care

2. Interdisciplinary team work

3. Evidence-based practice

4. Quality improvement

5. Informatics

For purposes of this discussion, the IOM defines competencies as "the habitual use of communication, knowledge, technical skills, clinical reasoning, emotions, values, and reflection in daily practice."

If a training system for family medicine residencies that is based on and responsive to the overarching family medicine system of care is designed and implemented, the recommendations of the IOM report will be addressed-and much more.

\section{FAMILY MEDICINE RESIDENCY EDUCATION}

The above observations provide a background and context in which to address the challenge of defining the educational elements necessary for the family physician of the future.
Vision and Mission of the Educational System

The vision and mission for family medicine residency education can be stated as follows:

Vision. To transform family medicine residency education into a process-oriented phenomenon that prepares and develops the family physician of the future to deliver, renew, and function within the family medicine system of care and to deliver the best possible care to the American people.

Mission. To create a flexible, process-oriented paradigm in family medicine residency education that trains family physicians to deliver patient-centered care consistently, as a member of an interdisciplinary team, emphasizing the biopsychosocial model, evidence-based practice, quality improvement, and informatics.

\section{Values of the Educational System}

In designing the family medicine training program of the future, it is important that the following values, as articulated in the IOM's studies, be clearly recognized and affirmed:

- Patient-physician relationship building-fostering positive patient-physician relationships, based on effective communication

- Safety-avoiding injuries to patients while providing medical care

- Effectiveness-providing evidence-based medical services

- Efficiency-avoiding waste in all areas of the system

- Patient centered-providing care that is respectful and that includes patient preferences, needs, and values

- Timeliness - care provided in a manner that minimizes waiting times and prevents harmful delays of care

- Equity - quality care provided in all geographic areas with no disparities because of gender, ethnicity, or socioeconomic status

- Accessibility - patients need to be able to access appropriate care when they need it

\section{Educational Guidelines}

As a visible demonstration of a commitment to these values, family medicine educators will need to translate them into guidelines for patient care within the medical education system.

Care Guidelines

Care guidelines are based on the following:

- Care is based on continuous healing relationships

- Customization is based on patient needs and values

- The patient is the source of control (care is goaloriented and negotiated with the patient)

- Knowledge is shared and information flows freely 
- Decision making is based on the best evidence available, and where evidence is lacking, it is sought through relevant and valid research

- Safety is a system property

- System operation is transparent at all levels

- Needs are anticipated

- Waste is continuously decreased

- All members of the health care team communicate and cooperate actively and fully

\section{Program Guidelines}

Similarly, changes in the structure and content of residency programs should be made, as appropriate, to further the goals and values articulated above:

- Flexibility and responsiveness-programs are able to provide education in areas needed to meet geographical and community needs.

- Innovation and active experimentation-programs are encouraged to try new methods of education, including 4-year curriculum pilot programs, and to teach the cutting edge of evidence-based medical knowledge.

- Consistency and reliability-programs provide a basic core of knowledge and produce family physicians who exemplify the values of the health care system articulated by the IOM.

- Individualized to learners' needs-programs offer expanded educational opportunities in areas needed by graduates, such as maternity care, orthopedics, and emergency care.

- Supportive of critical thinking-programs encourage and/or require research and expect a thorough understanding of evidence-based medical practice.

- Competency-based education-programs stress a new paradigm for evaluation of resident performance based on competency assessments.

- Scholarship and practice-based learning-programs integrate scholarship and quality improvement through analysis and interventions built around patient care activities in the continuity setting

- Integration of evidence-based and patient-centered knowledge - programs model knowledge acquisition and processing from both perspectives in the patient care setting.

- Medical informatics-programs go beyond just using an electronic health record to modeling the broad-based acquisition, processing, and documentation potential within state-of-the-art informatics resources

- Biopsychosocial integration-the biopsychosocial model is more than just adding psychosocial data. It is an approach that highlights the interrelationship among different levels of the system, for instance, the organ, the person, the family, the community, or the larger social context. It goes beyond introducing a different modality, or specialty, to propose a different method to clinical reasoning and care regarding all health issues. Although family medicine has recognized and attempted to incorporate the biopsychosocial model into its training, it has yet to integrate fully this way of thinking into all aspects of education and practice.

- Professionalism-programs move beyond the simple objectives of the ACGME professionalism curriculum requirements into a comprehensive monitoring and feedback system to residents during the critical developmental period of residency training.

- Collaboration-collaborative and interdisciplinary approaches to all learning-programs provide both support and role modeling for the effective use of teams and interdisciplinary approaches to patient care, including the involvement of other trainees in the process.

\section{INTERSECTION OF KNOWLEDGE, SKILLS, ATTITUDES, AND PRACTICE CHARACTERISTICS}

Appendix A contains an organizational grid of curricular areas under which the content of residency education can be organized. This grid is not an exhaustive list of specific items to be covered in any curriculum, but rather an attempt at organizing the essential elements of education into broad areas to facilitate a more comprehensive and integrated curricular design.

\section{Integrated Medical Care}

As health care becomes more complex and medical care becomes more interdependent with other health care services, family physicians of the future will need to be experts at integrating all aspects of care. Given the commitment in family medicine to a biopsychosocial model of care, family physicians will have a special role in promoting better integration of medical and mental health services. They will need to learn to work in teams and promote interdisciplinary collaboration in patient care, research, and education. Doing so will require special skills in the areas of teamwork, collaboration, organizational management, and leadership.

\section{Information Mastery}

As medicine and health care increase in detail and complexity, family physicians of the future will need to be expert managers of information, knowing how to ask the right questions and where to find the answers, how to determine the validity and reliability of those answers, how to integrate new knowledge into their practices, and how to recognize the need to question and discard old knowledge. 


\section{Population-Based and Public Health Perspective}

With growing emphasis on cost containment, resource management, and systems-based care, family physicians of the future increasingly will be expected to be adept at weighing population-based and public health considerations in their medical decision making.

\section{Scholarly Pursuit}

The ongoing development of the specialty and its need to contribute more substantially to the body of medical and health systems knowledge will depend on the growth of research and a greater commitment to a culture of ongoing inquiry in family medicine.

\section{Practice Management}

To run efficiently the family medicine practice of the future-while adapting to a changing practice environment and striving to deliver optimal patient and population-based care-family physicians will need more in-depth training in practice management, particularly involving electronic medical records and other information system applications.

\section{Professionalism}

Family medicine will need to challenge residents to strive for excellence in the provision of a model of care that promotes continuous self-reflection and commitment to ethical relationships and practice.

\section{Behavioral Medicine}

New challenges in health care and medical education provide an opportunity to reaffirm what has been an essential component of family medicine: relationshipcentered and contextual care. The behavioral sciences curriculum should provide the family physician with a framework that will be based on family systems and support the integration of mental health care into family medicine.

\section{Lifelong Learning}

To maintain the knowledge, skills, and attitudes necessary to achieve excellence in medical practice, family physicians must make a commitment to lifelong learning. That process must be modeled, supported, and initiated at the beginning of residency training.

\section{Advocacy}

Family physicians are positioned ideally to serve as the personal medical home for their patients. In this role, they must be advocates for their patients' needs and facilitate their patients' access into other areas of the health care system. They also must take on a larger advocacy role in society for accessible, cost-efficient, effective, high-quality health care for everyone.

\section{THE IMPACT OF CHANGING DEMOGRAPHICS}

Rapid changes in the demographics of the US population, including an aging population, with a shift toward a majority of minorities, ongoing immigration, and an increasing emphasis on multiculturalism_rather than a melting pot model-present new challenges to family physicians and the health care system as a whole. Physicians must grapple with issues of cultural differences; variable understandings of and approaches to health, illness, and health care; disparities in health and health care and special needs of certain populations. Additionally, the house of medicine itself is changing, with women and older students making up a growing percentage of the medical student and resident population, and with training institutions continually struggling with the need to train and promote more physicians from historically underrepresented minorities.

Current training models have attempted to address these issues by incorporating additional training in cultural competency. But to meet all of the challenges that are arising out of the changing demographics in the United States, family medicine education will need to take a comprehensive approach, integrating behavioral medicine and cultural proficiency into all curricular components, with attention to the special needs of various populations, recruitment and promotion of minority physicians, and systemwide advocacy into the overall educational structure.

\section{SUMMARY}

The task of designing and implementing a revised model of family medicine education is a work in progress. There are great opportunities and challenges associated with creating a new paradigm in family medicine residency education, which builds on the experience of the last 3 decades and prepares family medicine graduates for the next 3 decades. The key concept, which must be an integral part of whatever new systems are designed, is that the educational process must train competent family physicians who will provide the personal medical home for their patients. A personal medical home will require family physicians who understand and practice process-oriented care, who utilize the biopsychosocial model to create superb physician-patient relationships, who actively measure outcomes, and whose practices are driven by information system access to evidence-based principles of care.

\section{RECOMMENDATIONS}

Recommendation 1.1 That all family medicine organizations acknowledge the currently successful educa- 
tional model for family medicine is ripe for innovation and active experimentation to facilitate the discipline's advancement into the future.

Recommendation 1.2 That the foundational elements of family medicine education, which have produced family physicians competent in the core attributes of the discipline, be reaffirmed. Specifically, that training in maternity care and the care of hospitalized patients be reaffirmed as essential components of family medicine residency training.

Recommendation 1.3 That family medicine residency programs be supported through 5 to 10 years of curricular flexibility to permit active experimentation in competency-based education and other strategies to prepare graduates for the New Model of family medicine practice.

Recommendation 1.4 That, in the interest of promoting active experimentation in family medicine education, the relative merits of 3 -year vs 4 -year training programs be evaluated through a national experiment based in pilot programs approved by the ABFP and RRC-FP that will measure and report on learning, outcomes, costs, benefits, and disadvantages (Appendix B).

Recommendation 1.5 That every family medicine residency program implement an electronic health record system by 2006 .

Recommendation 1.6 That the following areas of emphasis within family medicine education be recognized as critical to producing consistently competent family physicians:

- Excellence

- A global content basis addressing the knowledge, skills, attitudes, and practice characteristics of family medicine (Appendix A)

- Patient-centeredness

- The biopsychosocial model

- Family, community, and population care

- Competency-based education

- Scholarship- and practice-based learning

- Evidence-based medicine

- Medical informatics

- Professionalism

- Accessibility and availability of care

- Office-based procedural skills

- Personal balance and awareness of growth

- Integration of care across systems

- Curricular flexibility to support the personal educational plans of individual trainees

- An emphasis on continuity settings

- Cultural proficiency and effectiveness

- Practice-based learning and improvement

Recommendation 1.7 That family medicine residency programs and departments should model, initiate, and be components of the support structure for lifelong learning in family medicine and the maintenance of certification for the discipline.

To read or post commentaries in response to this article, see it online at http://www.annfammed.org/cgi/content/full/2/suppl_1/S51.

Key words: Medical education; internship and residency; family practice; comprehensive health care

Members of the Task Force 2. John R. Bucholtz, DO, Chair, Columbus, Ga; Samuel C. Matheny, MD, MPH, Vice Chair, Lexington, Ky; John C. Anderson, MD, Cle Elum, Wash; Diane Kaye Beebe, MD, Jackson, Miss; Erika B. Bliss, MD, Seattle, Wash; Alan David, MD, Milwaukee, Wisc; Elizabeth Garrett, MD, MSPH, Columbia, Mo; Deborah G. Haynes, MD, Wichita, Kan; Bruce E. Johnson, MD, lowa City, lowa; Eliana C. Korin, Dipl Psic, Bronx, NY; Sandra Mendez, MD, Sacramento, Calif; James E. Zini, DO, Mountain View, Ariz; Perry A. Pugno, MD, MPH, CPE, Staff Executive, Leawood, Kan; Pamela Williams, Assistant Staff Executive, Leawood, Kan.

Acknowledgments: The task force benefited greatly from the input of many people, including all the members of the Future of Family Medicine Project Leadership Committee, the Family Medicine Working Party, FFM project and task force staff, members of the other FFM task forces, and particularly the group of external reviewers listed below.

Funding Support: The Future of Family Medicine Project is supported by the following family medicine organizations: American Academy of Family Physicians (AAFP), American Academy of Family Physicians Foundation (AAFPF), American Board of Family Practice (ABFP), Association of Departments of Family Medicine (ADFM), Association of Family Practice Residency Directors (AFPRD), North American Primary Care Research Group (NAPCRG), and Society of Teachers of Family Medicine (STFM). Major support has been contributed by: Eli Lilly Foundation; Pharmacia, Pharmacia Foundation; Pfizer, Pfizer Foundation; and the Robert Wood Johnson Foundation. In addition, generous support has been obtained from the Health Resources and Services Administration, Schering-Plough Corporation, and Wyeth Pharmaceuticals.

Project Leadership Committee: James C. Martin, MD, Project Leadership Committee Chair; Robert F. Avant, MD; Marjorie A. Bowman, MD, MPA; John R. Bucholtz, DO; John C. Dickinson, MD; Kenneth L. Evans, MD; Larry A. Green, MD; Douglas E. Henley, MD; Warren A. Jones, MD; Samuel C. Matheny, MD, MPH; Janice E. Nevin, MD, MPH; Sandra L. Panther, CFRE; James C. Puffer, MD; Richard G. Roberts, MD, JD; Denise V. Rodgers, MD; Roger A. Sherwood, CAE; Kurt C. Stange, MD, PhD; Cynthia W. Weber, MA.

Future of Family Medicine Research Advisory Committee: John R. Bucholtz, DO; John C. Dickinson, MD; Larry A. Green, MD; Warren A. Jones, MD; James C. Martin, MD; Richard G. Roberts, MD, JD; Kurt C. Stange, MD, PhD.

Future of Family Medicine Project Staff: Norman B. Kahn, Jr, MD, FFM Staff Executive; Sarah Thomas, Assistant Staff Executive; Marilyn A. McMillen, MBA, Project Manager; Dorothy Young, FFM Administrative Assistant; Nina Carnoali, FFM Staff Assistant; Ruth Coram, FFM Staff Assistant.

Reactor Panel: Diane Kaye Beebe, MD; Gregory H. Blake, MD; Richard Boothe II, MD; Richard Brunader, MD; Colleen Conry, MD; Samuel W. Cullison, MD; Alan K. David, MD; Charles E. Driscoll, MD; Ted Epperly, MD; Roxanne Fahrenwald, MD; Warren Heffron, MD; Terrence M. Leigh, EdD; Nancy Pandhi, MD; Perry A. Pugno, MD, MPH, CPE; James Puffer, MD; Mary Elizabeth Roth, MD; John W. Saultz, MD; Susan Schooley, MD; J. Lewis Sigmon, Jr, MD; Cynthia W. Weber, MA; Mary E. Willard, MD. 


\section{References}

1. American Academy of Family Physicians Research and Information Services Division. 2002 FACTS about family practice. Available at: http://www.aafp.org/x530.xml.

2. The Residency Education Subcommittee of the Academic Family Medicine Organizations and the Board of Directors of the Association of Family Practice Residency Directors. Strategic plan for residency education in family practice. Available at: http://www.afprd.org/plan/ index.html.

3. Accreditation Council for Graduate Medical Education. ACGME Outcome Project Web site. Available at: http://www.acgme.org.

4. Institute of Medicine. Committee on Quality of Health Care in America. Crossing the Quality Chasm: A New Health System for the 21st Century. Institute of Medicine. Washington, DC: National Academy Press; 2001

5. Greiner A, Knebel E. Institute of Medicine. Committee on the Health Professions Education Summit. Health Professions Education: A Bridge to Quality. Washington, DC: National Academy Press; 2003.

\section{Other Sources}

Action Plan for the Future of Residency Education in Family Practice. Recommendations of the AFMO/AFPRD Strategic Planning Working Group. January 1999. Available at: http://www.msecportal.org/portal/editorial/ PublicPages/afprd/536888546/actplan.html.

The College of Family Physicians of Canada. The JANUS Project: National Family Physician Workforce Study. October 2001. Available at: http: //www.cfpc.ca/English/cfpc/research/janus\%2-project/default.asp?s = 1 .

The Common Program Requirements, Accreditation Council for Graduate Medical Education, Chicago, Illinois. Effective July 1, 2003. Available at: http://www.acgme.org.

Duane M, Green LA, Dovey S, Lai S, Graham R, Fryer GE. Length and content of family practice residency training. J Am Board Fam Prac. 2002; 15:201-208.

The Family Medicine Curriculum Resource (FMCR) Project. Summary of Current Findings. April 2002. Available at: http://www.stfm.org/curricular/ fmcrmenu.htm.
The Future of Pediatric Education II (FOPE II) Project. Organizing Pediatric Education to Meet the Needs of Infants, Children, Adolescents, and Young Adults in the 21st Century. The American Academy of Pediatrics. Available at: http://www.aap.org/profed/fope1.htm.

Graham R, Roberts RG, Ostergaard DJ, Kahn NB, Pugno PA, Green LA. Family practice in 2001. A status report. JAMA. 2002;288:1097-1011.

Green LA, Dovey S, Fryer GE. It takes a balanced health care system to get it right. J Fam Pract. 2001; 50:1038-1039.

The Institutional Requirements, Accreditation Council for Graduate Medical Education, Chicago, Illinois. Effective: July 1, 2002. Available at: www.acgme.org.

Halvorsen JG. Family medicine's failures: reflections on Keystone III. Fam Med. 2001;33:390-392.

McPherson DS, Schmittling GT, Pugno PA, Kahn NB. Entry of US medical school graduates into family practice residencies: 2001-2002 and 3-year summary. Fam Med. 2002;34:575-583.

Phillips RL, Green LA. Making choices about the scope of family practice. J Am Board Fam Pract. 2002;15:250-257.

Program Requirements for Residency Education in Family Practice Accreditation Council for Graduate Medical Education, Chicago, Illinois. Effective: July 1, 2001. Available at: http://www.acgme.org.

Pugno PA, McPherson DS, Schmittling GT, Kahn NB. Results of the 2002 National Resident Matching Program: family practice. Fam Med. 2002;34: 584-591.

Qualitative and quantitative research data collected by Greenfield Consulting Group and Roper ASW, 2002. Available at: www.futurefamilymed.org.

The Residency Assistance Program (RAP) for Family Practice. Criteria for Excellence in a Residency Program. 5th ed. January 2003. Information on RAP is available at: http://www.aafp.org/x14265.xml.

Sandy LG, Schroeder SA. Primary care in a new era: disillusion and dissolution? Ann Intern Med. 2003;138:262-267.

SGIM Task Force on the Domain of General Internal Medicine. The Future of General Internal Medicine. 2003. Available at: http://www.sgim.org/ futureofGIMreport.cfm.

Starfield B. New paradigms for quality in primary care. Brit J Gen Prac. 2001;51:303-309. 


\begin{tabular}{|c|c|c|c|c|}
\hline & Knowledge & Skills & Attitudes & Practice Characteristics \\
\hline Medicine & $\begin{array}{l}\text { Preventive care } \\
\text { Acute care } \\
\text { Chronic disease care } \\
\text { End-of-life care } \\
\text { Mother-child care }\end{array}$ & $\begin{array}{l}\text { Procedures } \\
\text { Disease management } \\
\text { Critical reasoning } \\
\text { Critical inquiry }\end{array}$ & $\begin{array}{l}\text { Enjoys variety } \\
\text { Intellectually curious } \\
\text { Lifelong learning } \\
\text { Comfortable with } \\
\text { uncertainty } \\
\text { Intuitive }\end{array}$ & $\begin{array}{l}\text { Group care } \\
\text { Patient education } \\
\text { Patient covenant } \\
\text { Continuing medical education for } \\
\text { physicians and staff }\end{array}$ \\
\hline Patients & $\begin{array}{l}\text { Psychological knowledge } \\
\text { Sociocultural-economic } \\
\text { background } \\
\text { Belief and values systems } \\
\text { Genetic background } \\
\text { Family and relational context }\end{array}$ & $\begin{array}{l}\text { Consultation } \\
\text { Advocacy } \\
\text { Interviewing } \\
\text { Complexity management } \\
\text { Interpersonal and } \\
\text { communication skills } \\
\text { Sociocultural-economic } \\
\text { diversity } \\
\text { Patient education }\end{array}$ & $\begin{array}{l}\text { Caring } \\
\text { Empathetic } \\
\text { Responsive } \\
\text { Nonjudgmental } \\
\text { Values diversity } \\
\text { Relationship centered } \\
\text { Patient centered } \\
\text { Honest } \\
\text { Ethical }\end{array}$ & $\begin{array}{l}\text { Culturally sensitive practice } \\
\text { Accessible and available } \\
\text { Up to date } \\
\text { Responsive } \\
\text { Evaluation of patients sought }\end{array}$ \\
\hline Systems & $\begin{array}{l}\text { Evidence based medicine } \\
\text { Information management } \\
\text { systems } \\
\text { Quality assurance } \\
\text { Health care delivery systems } \\
\text { Health care financing } \\
\text { Public health }\end{array}$ & $\begin{array}{l}\text { Complexity management } \\
\text { Evidence-based medicine } \\
\text { Database skills } \\
\text { Coordinated team care } \\
\text { Partnering and collaboration } \\
\text { Negotiating } \\
\text { Integration of care across } \\
\text { systems }\end{array}$ & $\begin{array}{l}\text { Values quality } \\
\text { Pragmatic } \\
\text { Accountability } \\
\text { Responsibility } \\
\text { Accessible system } \\
\text { Cultural sensitivity } \\
\text { Participatory attitude } \\
\text { towards communities }\end{array}$ & $\begin{array}{l}\text { Research contributions } \\
\text { Just-in-time information } \\
\text { Electronic health record (EHR) } \\
\text { Asynchronous communications } \\
\text { Continuous quality improvement } \\
\text { Published quality measures } \\
\text { Group of } 3+\text { physicians } \\
\text { Open access } \\
24 / 7 \text { availability across the practice } \\
\text { Continuity across settings } \\
\text { Physician leadership } \\
\text { Integrated team-based care } \\
\text { Special interest skills developed in } \\
\text { each partner } \\
\text { Financially solvent } \\
\text { Community and population focused } \\
\text { practice }\end{array}$ \\
\hline Self & $\begin{array}{l}\text { Personal inventories } \\
\text { Beliefs, values, attitudes } \\
\text { Family and sociocultural } \\
\text { legacies }\end{array}$ & $\begin{array}{l}\text { Leadership } \\
\text { Personal and professional } \\
\text { balance } \\
\text { Time management }\end{array}$ & $\begin{array}{l}\text { Reflective } \\
\text { Self-aware } \\
\text { Humble } \\
\text { Committed to excellence }\end{array}$ & $\begin{array}{l}\text { Availability discussed } \\
\text { Scope of care discussed }\end{array}$ \\
\hline $\begin{array}{l}\text { Society and } \\
\text { populations }\end{array}$ & $\begin{array}{l}\text { Communities } \\
\text { Population-based health } \\
\text { Health disparities }\end{array}$ & $\begin{array}{l}\text { Advocacy } \\
\text { Sociocultural-economic } \\
\text { proficiency }\end{array}$ & $\begin{array}{l}\text { Committed to service } \\
\text { Committed to equity }\end{array}$ & $\begin{array}{l}\text { Community involvement } \\
\text { Population and practice database } \\
\text { kept }\end{array}$ \\
\hline
\end{tabular}


Appendix B. Three- and Four-Year Residency Curricula

\section{THREE-YEAR FAMILY MEDICINE RESIDENCY CURRICULUM}

Goal: Design a curriculum that emphasizes family medicine knowledge, skills, and attitudes in officebased care and coordination of care, and that allows flexibility to develop moderate focused ambulatory expertise in some areas.

\section{Family Medicine Expertise}

- Physician-patient relationships

- Chronic disease management

- Urgent/emergent care

- Community medicine

- Coordinated care

- Biopsychosocial model of care

- Proactive management of the practice

\section{Focused Expertise (Examples)}

- Geriatrics

- Sports medicine

- Behavioral medicine

- Adolescent medicine

- Office-based procedures

\section{Principles for Curriculum Design}

- Learning begins in the Family Practice Center/ ambulatory area and continues throughout the 3 years

- Occur in an open-access practice that is accessible, available, and efficient

- Emphasize the development of physician-patient relationships over time

- Emphasize continuous quality improvement, both in the process of care and in the outcomes of care

- Teach management of the practice and its population utilizing:

1. Practice rounds

2. Active precepting

3. Proactive patient interventions

- Utilize electronic information systems to monitor physician activity, patient care quality and practice outcomes

- Become the primary site for much of the ambulatory subspecialty teaching: procedures, orthopedics, otolaryngology, dermatology, etc

- Hospital rotations deemphasized as part of the educational experience
- The doctor-patient relationship is a fundamental part of the practice, learning and evaluation

- This relationship is maintained throughout a variety of health care settings

- Competency measures of knowledge, skills, and attitudes are both periodic and ongoing and form the basis for advancement

- Management of the practice from an individual to a population perspective is emphasized

\section{FOUR-YEAR FAMILY MEDICINE CURRICULUM}

Goal: Design a curriculum that generates additional knowledge, skills, and attitudes in family medicine and facilitates attainment of in-depth expertise in 1 or 2 domains of family medicine.

\section{Family Medicine Expertise}

- Physician-patient relationships

- Chronic disease management

- Urgent/emergent care

- Community medicine

- Coordinated care

- Biopsychosocial model of care

- Proactive management of the practice

\section{Focused Expertise (Examples)}

- Geriatrics

- Obstetrics/women's care

- Sports medicine

- Adolescent medicine

- Behavioral medicine

- Research/teaching

- In-patient care

- Rural care

- Advanced procedural abilities

\section{Principles for Curriculum Design}

- First 3 years build toward the fourth year

- Ambulatory focus, from start to finish

- An individual program may be able to offer only 1 or, at most, a choice of 2 focused areas for the year

- Competency measurements would run through the program 